\title{
Identifying the Needs of Prekindergarten Children: A Focus on Health, Wellbeing, and Family Environment
}

\author{
Xumei Fan ${ }^{1}$ (1) $\cdot$ Sandra Linder ${ }^{2} \cdot$ Leigh Kale D'Amico $^{3} \cdot$ Kelley Mayer White $^{4} \cdot$ Tammy Pawloski $^{5}$
}

Accepted: 30 April 2021 / Published online: 18 May 2021

(c) The Author(s), under exclusive licence to Springer Nature B.V. 2021

\begin{abstract}
The impact of children's health, wellbeing, and family environment on their learning and development is evident. Identifying the needs of children and their families is the first step to effectively developing and implementing programs that promote child development. This research employed a convergent mixed methods design and incorporated multiple data collection and analysis techniques to explore the needs of prekindergarten children related to their health, wellbeing, and family environment. A large-scale survey, regional meetings, and focus groups were conducted among a total of 4615 parents/caregivers, organizational representatives, and community members in the state of South Carolina, in the United States. Understanding child development, getting services for children and families, making childcare accessible and affordable, having enough family time, building strong relationships with children, and community support for families were identified as priorities. Parents/caregivers of different socio-demographic backgrounds prioritized different needs.
\end{abstract}

Keywords Prekindergarten children $\cdot$ Needs assessment $\cdot$ Health and wellbeing $\cdot$ Family environment $\cdot$ Mixed methods

\section{Introduction}

Xumei Fan

fan9@email.sc.edu

Sandra Linder

sandram@g.clemson.edu

Leigh Kale D’Amico

damico@mailbox.sc.edu

Kelley Mayer White

whitekm@cofc.edu

Tammy Pawloski

tpawloski@fmarion.edu

1 Department of Educational Studies, University of South Carolina, 004 Wardlaw, Columbia, SC 29208, USA

2 Early Childhood Mathematics Education, Clemson University, 407-F Tillman Hall, Clemson, SC 29634, USA

3 Research, Evaluation, and Measurement Center, University of South Carolina, 820 South Main Street, Columbia, SC 29208, USA

4 Department of Teacher Education, College of Charleston, 66 George Street, Charleston, SC 29424, USA

5 FMU Center of Excellence to Prepare Teachers of Children of Poverty, Francis Marion University, PO Box 100547, Florence, SC 29501, USA
Early childhood is a critical period of human development, and it lays the foundation for lifelong success. Healthy development of the "whole child" involves three important areas: early childhood education, health and wellbeing, and family or home environment. Research has documented that early childhood education is essential for later academic success in school. Children who attended a center or school-based program in the year before school entry performed better on reading and math in kindergarten (Magnuson et al., 2004). Early childhood intervention programs are especially beneficial for children from disadvantaged families. Wright et al. (2017) indicated that children experiencing homelessness in the community-based $4 \mathrm{~K}$ programs performed better in both math and language arts in second grade, in comparison with children experiencing homelessness who did not attend early childhood programs.

Health and wellbeing are fundamental for child development. A National Survey of Children's Health (NSCH) reported that about $19 \%$ of children in the United States had a special health care need, and about one in four households had one or more children with special health care needs in 2017-2018 (U.S. Department of Health and Human Services, 2020). Therefore, it is crucial to identify the needs of 
children and provide appropriate intervention and support to them. When considering meeting the needs of children, home is the most important setting. Various studies found that a supportive family environment is beneficial in fostering child developmental outcomes (Dunst et al., 2008), and family literacy is essential for early learning and development (Clay, 1966; Crawford \& Zygouris-Coe, 2006; Jacobs, 2004). However, research also revealed disparities and gaps between children from advantaged and those from disadvantaged families (Magnuson et al., 2004). The differences were found to be associated with household income (Fryer \& Levitt, 2006; Reardon, 2011), housing instability (Ziol-Guest \& McKenna, 2014), parent education (Kalil et al., 2012), and ethnicity/race (Magnuson \& Waldfogel, 2016).

A large-scale, statewide needs assessment was conducted through the lens of multiple stakeholders to address the needs of children and their families. The importance of needs assessments was described in the framework of access to quality early childhood education and care developed by Archambault et al. (2020), in which identification of childcare needs and the perceptions of need and desire for childcare are listed as the initial steps. This study was an initiative of a Preschool Development Grant (PDG) awarded by the US Department of Health and Human Services. The overall PDG project places a heavy emphasis on understanding the needs of all children across South Carolina, with an explicit focus on the systemic racism that pervades society and an emphasis on how this work might inform access and equity in educational settings. The major purpose of this study was to identify the needs of young children regarding their health, wellbeing, and their family and home environments, and the ultimate goals were to inform the development and implementation of strategic plans, support children and families, and promote early learning and development. While the findings presented in this article may not disentangle the systems that promote inequity across the United States, they act as a starting point aimed at understanding the perceived needs of families across demographics.

\section{Child Health and Wellbeing}

Health has been conceptualized as an absence of illness and disease, a strength, and functional fitness (Williams, 1983), a state of complete physical, mental, and social well-being (World Health Organization, 1946), and a personal responsibility (Easthope \& White, 2006). The term "wellbeing" has been interchangeably used with "wellness," "comfort," and "quality of life" in the context of health (Kiefer, 2008; Moore et al., 2012). Wellness is defined as the positive end of a graduated spectrum of health (Larson, 1999), and an individual's ability to function and fulfill social responsibilities (Spurr et al., 2012). Wellbeing is conceptualized as an individual's physical, mental, social, and environmental status (Kiefer, 2008), and viewed as a multidimensional construct (Corbin \& Pangrazi, 2001; Corbin et al., 2002; Simon et al., 2008). Corbin and Pangrazi (2001) described five subdimensions of wellbeing, which include physical, social, emotional, intellectual/mental, and spiritual. Specifically, the physical subdimension of wellness includes health habits, receipt of preventive health care services, and physical activity levels (Spurr et al., 2012).

Children who are healthy early in life become healthier, better educated adults. The majority of research on the health and wellbeing of young children has focused on appropriate prenatal care, and on the influence of nutrition and universal immunization (Rossin-Slater, 2015). In particular, Easthope and White (2006) studied the perceptions of health and wellbeing of school-age young people (the age range was from 11 to 18 years), finding that young people achieve good health by eating the right foods, exercising, and avoiding bad habits. They achieve wellbeing by having a circle of friends and a supportive family. The researchers also found that young people's mental health and their feeling of wellbeing is dependent upon the nature of their social networks, and family, especially "mum," plays a large part in young people's sense of wellbeing (Easthope \& White, 2006). Studies also found that early childhood programs could promote child health and wellbeing. For example, Head Start, a federal program providing comprehensive early childhood education, health, nutrition, and parent involvement services to low-income children and families, was found to help reduce the likelihood of child obesity (Frisvold \& Lumeng, 2011) and mortality (Ludwig \& Miller, 2007).

Children with special health care needs are the focus of many studies. Chen and Cisler (2011) found that summary scores of health-related quality of life measures were lower for children with special health care needs in comparison with those without special health care needs, and younger age of children, lower SES, health care access barriers, and poor maternal health were associated with lower healthrelated quality of life for children. Simon et al. (2008) found that children's lower health-related quality of life is associated with lower family education, single-mother family, Black race, poverty, older age group, and having a smoker in the household. In particular, ethnic and racial disparities were found regarding access to health care among children with special health care needs (Newacheck et al., 2002). African American children with special health care needs had lower health-related quality of life compared to Caucasian children with special health care needs, and children with special health care needs from non-English primary language households and those from single-parent households had lower health-related quality of life (Chen \& Cisler, 2011). 


\section{Family and Home Environment}

Family and home environments are important for children and their families to thrive. The U.S. Census Bureau (2020) defines a family as "a group of two people or more (one of whom is the householder) related by birth, marriage, or adoption and residing together." Family and community life are viewed as two major contexts of children's learning in addition to early childhood programs in which children formally participate (Dunst et al., 2000). A supportive family environment is beneficial in fostering child developmental outcomes (Dunst et al., 2008). Specifically, families provide support to children's development by their responsiveness to children's needs, positive interactions with children, expectations for their children, and their efforts to build positive relationships with children and family members (Dunst et al., 2006, 2008; Landry et al., 2006; McWilliam \& Scott, 2001).

The impact of family environment on children's literacy learning has been documented by various studies. Crawford and Zygouris-Coe (2006) described literacy learning as rooted in the home experience, and families viewed literacy learning as a path to improving their life circumstances. Clay (1966) claimed children learned a lot about literacy in their home environments, and family literacy is essential for early learning and development (Jacobs, 2004). Family literacy interventions can have a substantial effect on children's reading acquisition in kindergarten and beyond (Senechal \& Young, 2008), and children who engage in dialogic reading with their families tend to exhibit stronger vocabulary skills (Mol et al., 2008). There is growing evidence in the research literature of the potential impact that high-quality mathematics experiences in home environments have on children's understandings of mathematics and how these skills support children as they enter kindergarten and navigate later school years (Linder \& Emerson, 2019; Linder et al., 2013). Highquality family mathematics interactions can lead to increased school readiness and enhanced dispositions towards mathematics as a discipline (Ginsburg, 2007; Hanline et al., 2010; Linder \& Emerson, 2019; Verdine et al., 2014).

Researchers identified preschool enrollment gaps between children from advantaged and those from disadvantaged families (Magnuson et al., 2004). Disparities existed in children's academic achievement associated with family income when entering kindergarten, and these disparities persisted through school (Fryer \& Levitt, 2006; Reardon, 2011). Chetty et al. (2016) found that moving to a neighborhood with a lower poverty index before age 13 increases college attendance and earnings. Ziol-Guest and McKenna (2014) found that moving three or more times in a child's first five years of life is significantly associated with increases in attention problems, and with internalizing and externalizing behavior. Studies found that adverse parenting behaviors are common among low-income families, and having a homeless episode was significantly related to increased instances of physical aggression toward a child (Park et al., 2015).

Disparities in child development were also identified between families of different ethnicity/race identities. White children from higher-income families were more likely to attend preschools in comparison with non-White children and those from lower-income families (Magnuson \& Waldfogel, 2016). Child development was also related to parent education and the quality time that parents spent with their children. According to Kalil et al. (2012) and Ramey and Ramey (2010), college-educated parents invested more quality time with their children than those without a college degree. It is important to acknowledge that racial/ethnic minority status is not the risk factor for the disparities and gaps in child development outcomes. Instead, multiple family-level factors including socioeconomic status, employment, education, family structure, as well as bias and racism at a macro- and micro-level impact the accessibility and affordability of services for children and families.

\section{The Current Study}

While the studies reviewed demonstrate the effectiveness of early childhood educational programs (Magnuson et al., 2004), the importance of child health and wellbeing, and the impact of family environment on learning and development (Crawford \& Zygouris-Coe, 2006), limited research has focused on identifying familial health and wellbeing needs from the perspective of the parents/families themselves. Jain et al. (2020) conducted a needs assessment of the systems of care for young children with social-emotional and behavioral concerns. They indicated that families from racially, ethnically, and linguistically diverse backgrounds demonstrated distinct needs, and they advocated for systems of care that are designed with these risk and protective factors in mind. An unpublished study by the same research team revealed associations between the socio-demographic identities of parents/caregivers and their choices of priorities regarding child needs in education.

The current study was an initiative of the Preschool Development Grant (PDG) awarded to South Carolina (SC) by the US Department of Health and Human Services. While South Carolina is influenced by national contexts, it also has unique socio-demographic characteristics and functions within its own unique state-based values and beliefs. It is significant to identify the unique needs of children and families in SC in order to provide corresponding intervention and support. This study sought to understand the perspectives of various stakeholders, including parents/caregivers, organizational representatives, and community members regarding the needs of prekindergarten children and their families. A survey, regional meetings, and focus groups were conducted 
among a total of 4615 parents/caregivers, organizational representatives, and community members in South Carolina. The study was intended to address the following questions:

(1). How do multiple stakeholders, including parents/caregivers, community members, organizational representatives, and community/state leaders, identify or describe priorities of health, wellbeing and family environments for young children?

(2). What relationships exist between parents/caregivers' socio-demographic information and their priorities of health, wellbeing and family environment?

(3). How do data from multiple sources triangulate in the development of common goals and priorities across stakeholders?

\section{Methods}

This study represents a small part of a larger statewide needs assessment focused on determining the perceived needs of young children across South Carolina by ascertaining perceptions from a variety of stakeholders involved in early childhood education, growth, and development. The larger needs assessment was focused on identifying and defining variables that can support systemic change through future early childhood initiatives implemented throughout the state. This work was grounded in Bronfenbrenner's (1986) Ecological Systems Theory where the child, family, school, and community are viewed as interacting microsystems. The interactions between and within these systems ultimately determine the trajectory of a child's development (Bronfenbrenner, 1986); and, through a series of process-person-context models (Bronfenbrenner, 2005), result in development occurring in a bidirectional manner. The Ecological Systems Theory emphasizes environmental factors as central to early childhood development. Through interactions with varying systems such as the child's family, school, and community organizations, the child is exposed to various norms and rules that help shape his or her cognitive and psychological development (Bronfenbrenner, 1986).

The researchers used Bronfenbrenner's framework to design a conceptual framework for the research design that employed a mixed-methods convergent design (Creswell \&
Plano Clark, 2018). Quantitative and qualitative data were collected and analyzed separately and then mixed to investigate prekindergarten children's needs through the lens of parents/caregivers, organizational representatives, and community members (see Fig. 1). Quantitative data were collected using a large-scale, state-wide online survey aimed at understanding the priorities of child needs related to health, wellbeing, and family environment. Qualitative data were collected through state-wide regional meetings and focus groups attempting to explore in-depth the overarching goals and specific goals related to child development, as well as the barriers that might prevent stakeholders from achieving the goals. Following individual analyses of each data collection stage, the IHE Collaborative conducted a secondary analysis across all results to determine how participants across groups described the needs of prekindergarten students across the state in relation to health, wellbeing, and family environments. The data collection methods and analysis techniques for each of these phases are described below.

\section{Survey}

An online survey was developed and distributed through SurveyMonkey to parents/caregivers, representatives of organizations serving young children and parents, and community members to understand their views of the priorities for child development. Data collection was spearheaded mainly through a partnership with the state-level First Steps, a nonprofit and state agency focusing on getting children ready for school and life success. Each First Steps partner was provided a customized link to the survey to enable tracking of responses by county. Further, a general link was distributed to other organizations and entities to expand access to the survey. In addition, social media and other state and local agencies and organizations (e.g., South Carolina Department of Social Services, South Carolina Early Childhood Association) distributed the survey to the general public. Communities were contacted by the partner organizations located in all 46 counties in the state, and members who were interested in the issues related to children and families completed the survey.

The survey items were aligned with three factors including early learning and development, health and wellbeing, and family environment, and were developed by the IHE
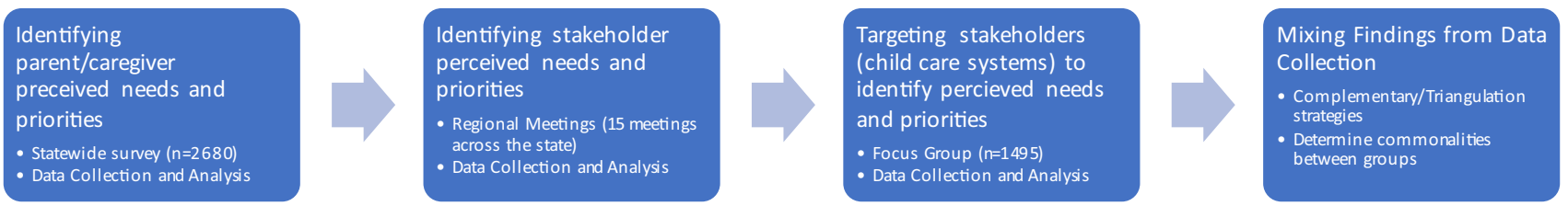

Fig. 1 Conceptual framework 
Collaborative based on the review of research literature (Archambault et al., 2020; Dunst et al., 2000, 2006; Easthope \& White, 2006; McWilliam \& Scott, 2001; Spurr et al., 2012) and other needs assessments (e.g., Jain et al., 2020). Experts in the field of early childhood education, equity and family support, and survey design reviewed the survey to ensure the validity of the instrument. This study focused on health and wellbeing with 12 items (Table 2), and family and community with 11 items (Table 6).

Respondents were asked to select their top three priorities among all the indicators related to child development. We used this method rather than a Likert scale of importance because all indicators are relevant to child development and we were concerned participants, especially parents/caregivers, might select all aspects as very important, which would limit our ability to identify priorities. In addition, we did not require the participants to rank order all indicators since doing so for more than ten items in each domain might create confusion or frustration for them. We used their selection of three primary priorities to help us identify, understand, and focus on parents/caregivers' needs that should be prioritized in the process of strategic planning.

A total of 2680 participants from 44 counties in South Carolina were included in the analysis. Among them, 1216 (45.4\%) were parents or caregivers, 1134 (42.3\%) were representatives of organizations that work with children and families, and $330(12.3 \%)$ were community members. Demographic information was requested from those who identified as parents or caregivers. Among the 1216 parents/caregivers (Table 1), about 50\% were Black or African American, $44 \%$ were White or Caucasian, $2 \%$ were Hispanic/Latino, $2 \%$ had more than one race/ethnicity identities, $1 \%$ were Asian, and $0.4 \%$ were American Indian or Alaska Native or Native Hawaiian or other Pacific Islander. About $22 \%$ had a master's degree or above, $19 \%$ had a bachelor's degree, $16 \%$ had an associate's degree, and $43 \%$ had some college or high school diploma/GED or below. About $18 \%$ were 25 years of age or younger, 53\% were between 26 and 40 years of age, and $29 \%$ were older than 40 . About $63 \%$ were employed and worked full time, $22 \%$ worked part time, and $15 \%$ were in the other employment categories (e.g., not employed, retired, experiencing disability). About $41 \%$ of the parents/caregivers reported having two or more young children who were five years old or younger, and about 59\% reported having one child who was five years old or younger or no child in the age range.

We examined whether the survey sample is representative of the population in South Carolina. According to the United States Census Bureau (2019), about $67 \%$ of the population in South Carolina were White, $27 \%$ were Black or African American, 2\% had two or more races, $2 \%$ were Asian, $0.4 \%$ were Native American, $0.1 \%$ were Native Hawaiian or Pacific Islander, and 2\% had Other Race. The survey sample
Table 1 Parents/Caregivers' demographic information

\begin{tabular}{|c|c|c|}
\hline Demographic variable & $\mathrm{N}$ & $\%$ \\
\hline \multicolumn{3}{|l|}{ Ethnicity/Race } \\
\hline Black/African American & 586 & 49.5 \\
\hline White & 526 & 44.4 \\
\hline Hispanic/Latino & 29 & 2.4 \\
\hline Two or more races & 24 & 2.0 \\
\hline Asian & 16 & 1.4 \\
\hline American Indian or Alaska Native & 3 & 0.3 \\
\hline Native Hawaiian or other Pacific Islander & 1 & 0.1 \\
\hline \multicolumn{3}{|l|}{ Academic degree } \\
\hline High school diploma/GED or below & 277 & 23.2 \\
\hline Some college (no degree) & 237 & 19.8 \\
\hline Associate's & 195 & 16.3 \\
\hline Bachelor's & 223 & 18.7 \\
\hline Master's or Doctorate & 262 & 21.9 \\
\hline \multicolumn{3}{|l|}{ Age } \\
\hline 25 or under & 218 & 18.1 \\
\hline $26-40$ & 636 & 52.7 \\
\hline Above 40 & 353 & 29.3 \\
\hline \multicolumn{3}{|l|}{ Employment status } \\
\hline Full time & 749 & 63.3 \\
\hline Part time & 262 & 22.1 \\
\hline Other & 172 & 14.5 \\
\hline \multicolumn{3}{|l|}{ Number of young child (Birth to Age 5) } \\
\hline No young child (Birth to Age 5) & 248 & 20.4 \\
\hline 1 young child (Birth to Age 5 ) & 473 & 38.9 \\
\hline 2 young children (Birth to Age 5) & 300 & 24.7 \\
\hline 3 or more young children (Birth to Age 5 ) & 194 & 16.0 \\
\hline
\end{tabular}

included a larger percentage of Black parents/caregivers and a smaller percentage of White parents/caregivers. Regarding education, about $11 \%$ of the population in South Carolina had a graduate or professional degree, $18 \%$ had a bachelor's degree, $10 \%$ had an associate's degree, $20 \%$ had some college, and $29 \%$ had a high school or equivalent degree. It appears that the survey sample had larger percentages of parents/caregivers with a graduate degree. It is important to note that the survey targeted parents/caregivers along with organizational representatives and community members who serve children and families, which might not represent the general population of South Carolina.

We analyzed the survey data based on the research questions. First, we compared the views of parents/caregivers, organizational representatives, and community members, reporting the percentages of participants who selected each item as a priority. Second, we focused on the views of parents/caregivers by considering their socio-demographic information including age, race/ethnicity, academic degree, employment status, and number of young children. We used binary logistic regression to 
Table 2 Needs in health and wellbeing $(\%)(\mathrm{N}=2680)$

\begin{tabular}{llll}
\hline Indicators & $\begin{array}{l}\text { Parents/ } \\
\text { Caregiv- } \\
\text { ers }\end{array}$ & $\begin{array}{l}\text { Organizational } \\
\text { representatives }\end{array}$ & $\begin{array}{l}\text { Community } \\
\text { members }\end{array}$ \\
\hline Understanding child or children's development & 48.8 & 47.1 & 36.7 \\
Finding healthcare providers for child or children & 27.1 & 14.9 & 20.0 \\
Taking child or children to well-child visits & 30.5 & 28.0 & 24.5 \\
Being able to afford healthcare for child or children & 32.3 & 37.7 & 49.1 \\
Being able to get to healthcare as needed for child or children & 28.1 & 39.8 & 39.4 \\
Getting services for needs of child or children & 35.0 & 54.9 & 47.3 \\
Having time to prepare healthy meals for child or children & 29.4 & 13.7 & 15.5 \\
Being able to find nutritious foods & 22.3 & 9.4 & 16.1 \\
Having safe food and drinking water & 22.0 & 8.8 & 12.1 \\
Being able to afford nutritious foods & 23.0 & 19.8 & 27.0 \\
Having mental health services for child or children & 14.7 & 28.5 & 23.0 \\
Having mental health services for parents or caregivers & 15.9 & 24.0 & 20.9 \\
\hline
\end{tabular}

explore whether parents/caregivers from different backgrounds selected different priorities. In the logistic regression model, parents/caregivers' selection of the items (Yes/ No) was the dependent variable, and their age, race/ethnicity, academic degree, employment status, and number of young children were predictors. Because the independent variables are categorical data, these variables were dummy coded, a decision based on the initial descriptive statistics. We calculated the percentages of parents/caregivers who selected each item as a priority based on their age, race/ ethnicity, academic degree, employment status, and number of young children. We observed that parents/caregivers demonstrated similar perspectives across some levels within the independent variables, and we then made decisions on the cutoff. For example, we initially calculated percentages of parents/caregivers based on all five levels of their academic degree. We noticed that parents/caregivers with a bachelor's degree and those with a master's or doctorate had very similar percentages. Parents/caregivers who had an associate's degree, some college, and high school diploma/GED or below had similar percentages. Therefore, we decided to use bachelor's degree as a cutoff. We used the same decision-making process for the dummy coding of other independent variables. For race/ ethnicity, White was the reference group and coded as 0 , Black and Other were coded as 1, separately. For age, 25 or younger was the reference group and coded as 0 , age between 26 and 40 and older than 40 were coded as 1 , separately. For employment, full-time was the reference group and coded as 0 , part-time and other were coded as 1, separately. For degree, below bachelor's degree was the reference group and was coded as 0 , and bachelor's degree or above was coded as 1 . For the number of children, 0 or 1 child was the reference group and coded as 0 , and two or more children was coded as 1 . Based on the analysis, odds ratios were reported.

\section{Regional Meetings}

Fifteen regional meetings/sessions were held in 13 different urban, suburban, or town/rural locations in the state. Each regional meeting lasted about two hours. To identify the meeting locations, the researchers used the four regions (Upstate, Midlands, Low Country, and Pee Dee regions) designated by the Child Care Licensing office of the South Carolina Department of Social Services. Three meetings were held in differing locations within each region, and two additional meetings were held during evening hours in two of the largest metropolitan areas in the state. These 14 regional meetings were open-access meetings that were advertised through multiple state and local organizations including South Carolina Department of Social Services, South Carolina First Steps, and the South Carolina Association for the Education of Young Children. One additional regional meeting was held at the South Carolina Head Start Association/South Carolina Association of Community Action Partnerships Conference with access limited to those attending the conference. Further, as representatives of the IHE Collaborative were designated from each region of the state, they used snowball sampling to recruit participants from their local networks (including, but not limited to, parenting groups, educational sites, community organizations). Sign-in sheets were used at each meeting to track attendance and gather participants' professional affiliation.

Facilitators used a standard PowerPoint presentation during the first portion of each meeting to explain the needs assessment process and to set the agenda for the meeting. This presentation was developed during biweekly meetings 
of the IHE Collaborative to ensure consistency and fidelity in terms of implementation. In the first phase of regional meetings, participants discussed and identified overarching goals and specific goals in small groups. Following this first phase of meetings, facilitators collected notes and identified goals from small groups and all artifacts were inputted into a spreadsheet to allow for open coding analysis (Corbin \& Strauss, 2008). Following this analysis, the IHE Collaborative created a synthesized list of overarching and specific goals used to facilitate the second phase of regional meetings. In this second phase, participants worked in small groups to develop and refine priorities based on the synthesized goals identified through open coding and to discuss current barriers in achieving the goals. Following this second phase of meetings, all meeting notes were transcribed and inputted into a spreadsheet and qualitatively analyzed using open coding, followed by axial coding (Corbin \& Strauss, 2008) to identify commonalities across regions. Four researchers from the IHE Collaborative coded the meeting notes, summarized the codes, and constructed themes and sub themes collaboratively.

\section{Focus Groups}

To gain more in-depth local-level feedback, South Carolina First Steps, in collaboration with their local-level partners, conducted focus groups based on an implementation guide that included a planning document, the focus group protocol, and a reporting template aligned with the protocol. This planning guide was created by the IHE Collaborative to ensure fidelity across facilitators. As this was a statewide initiative, facilitators were recruited from First Steps county offices to ensure positive rapport with participants rather than having researchers external to the community conduct each focus group. The common protocol and training for facilitators was an attempt for the IHE Collaborative to control for the large number of facilitators involved in data collection. Focus group interviews were conducted within 46 counties across the state. At least one focus group was conducted within all 46 counties across the state. Suggestions related to recruiting focus group participants were provided to First Steps partners based on their current networks within the county with an emphasis on ensuring parents and caregivers of young children were represented. Researchers did not request sign-in sheets from the focus groups but documented the numbers of participants within three categories. Researchers also do not know if the focus group participants were representative of the population within the county.

The total number of people who participated in focus groups was 1495; 911 (61\%) were parents and caregivers, 418 (28\%) were organizational representatives, and 166 (11\%) were others. While we did not gain specific information about those who did not identify as parents/caregivers or organizational representatives, it is believed these were community members/leaders interested in early childhood issues and teachers who may not specifically identity themselves as organizational representatives. First Steps designees who assisted with and/or facilitated the focus groups provided summaries of the focus group interviews conducted within their respective counties via SurveyMonkey.

Following focus groups in each county, facilitators transcribed notes and summarized overall findings collected through SurveyMonkey to enable the IHE Collaborative to access this large amount of data in a single system. Following focus group implementation, the researchers analyzed the 46 focus group summaries using open coding techniques (Corbin \& Strauss, 2008) and a secondary analysis of the data was then conducted to determine commonalities across the state. R for Qualitative Data Analysis (RQDA) was used to assist with coding given the large number of participants.

\section{Data Mixing}

The IHE Collaborative used complementary mixing strategies (Bazeley \& Kemp, 2012) to mix quantitative survey data with qualitative interview data to determine overall results. This complementary mixing process refers to what Bazeley and Kemp (2012) describe as, "combining to detail a more significant whole." By looking for points of triangulation between the inductive and deductive nature of the data, the project team would be able to tell a greater story than if the parts were separated into smaller subplots. Further, the IHE Collaborative took steps throughout the study to ensure a high level of validity, trustworthiness, and legitimation (Johnson \& Onwuegbuzie, 2004). Survey development was reviewed for construct and content validity by a group of experts in early childhood research. In addition, a secondary review was conducted by an expert in social justice in early childhood education to ensure items were presented without bias. The IHE Collaborative created protocols that guided all regional meetings and focus groups. The Collaborative conducted regional meetings to ensure consistency within protocol use and provided training for all focus group facilitators to ensure fidelity.

\section{Study Design Limitations}

There are a few limitations in the design of this study. First, in the survey design, we asked the respondents to select their top three priorities regarding child health, wellbeing, and family environment. This type of survey scale is aligned with our research questions, but we are also aware that asking participants' selections of their top three priorities might result in their neglect of other factors. We assumed that all aspects within the survey domains are important in child development, and parents/caregivers of different 
sociodemographic backgrounds identify different priorities regarding child health, wellbeing, and family environment. This study design limitation should also be considered when drawing conclusions based on the results. Second, because the survey did not use a random sampling method, the parents/caregivers participated in this study might not fully represent the population in the state, and the voices of parents/ caregivers who were homeless or transient might not have been heard. Third, the survey study focused on the perceptions of the priorities from parents/caregivers, and we collected their demographic information to better understand child need. However, we did not collect the demographic information of the organizational representatives and community members, and we would not be able to recognize possible differences in their views based on their sociodemographic background. In addition, in the regional meetings and the focus groups studies, we did not collect the specific demographic information of the participants although we used strategies to try to recruit participants from various backgrounds. These limitations in the study design should be addressed in future studies.

\section{Results}

\section{Survey Results}

Survey results were reported separately for the needs related to health and wellbeing and those related to family environment. We first compared the views of parents/caregivers, organizational representatives, and community members regarding their selection of priorities. Then we reported the views of parents/caregivers by considering their age, race/ ethnicity, highest academic degree, employment status, and number of young children. In addition, we used binary logistic regression to explore whether the likelihood for parents/ caregivers to select an item as a priority differed based on their background information. The significance level $\alpha$ was set to be 0.05 .

\section{Needs or Priorities Related to Health and Wellbeing}

We compared the perspectives of parents/caregivers, organizational representatives, and community members regarding the priorities of children's health and wellbeing (Table 2). For parents/caregivers, almost half (48.8\%) selected "Understanding child development" as a priority, and about onethird selected "Getting services for needs of children" and "Being able to afford healthcare for children" as priorities. For organizational representatives, about half selected "Getting services for needs of children" and "Understanding child development" as priorities. For community members, about half selected "Being able to afford healthcare for children" and "Getting services for needs of children" as priorities.

We then analyzed the perspectives of parents/caregivers regarding child health and wellbeing by considering race/ ethnicity, age, academic degree, employment status, and number of young children (Tables 3 and 4). We also used binary logistic regression analyses to examine the prediction of age, race/ethnicity, academic degree, employment status, and number of young children on their selection of priorities. Odds ratios (OR) were reported in Table 5.

Parents/caregivers of different ethnicity/race identities demonstrated differences in their priorities for some aspects in health and wellbeing. For example, about $13 \%$ of White parents/caregivers and $31 \%$ of Black parents/caregivers selected "Having safe food and drinking water" as a priority, with Black parents/caregivers reporting significantly greater likelihood $(\mathrm{OR}=2.49)$ of selecting this item as a priority while controlling other variables in the model. About $23 \%$ of White parents/caregivers, $32 \%$ of Black parents/caregivers, and $34 \%$ of the parents/caregivers of
Table 3 Needs in health and wellbeing based on ethnicity/ race and age $(\%)$

\begin{tabular}{|c|c|c|c|c|c|c|}
\hline \multirow[t]{2}{*}{ Indicators } & \multicolumn{3}{|c|}{ Race/Ethnicity } & \multicolumn{3}{|l|}{ Age } \\
\hline & Black & White & Other & $26^{-}$ & $26-40$ & $40^{+}$ \\
\hline Understanding child or children's development & 53.1 & 44.3 & 47.9 & 54.6 & 46.9 & 49.0 \\
\hline Finding healthcare providers for child or children & 29.2 & 24.0 & 32.9 & 34.4 & 26.7 & 23.5 \\
\hline Taking child or children to well-child visits & 30.2 & 30.2 & 31.5 & 37.2 & 31.3 & 25.8 \\
\hline Being able to afford healthcare for child or children & 34.1 & 29.5 & 34.2 & 31.7 & 33.2 & 30.9 \\
\hline Being able to get to healthcare as needed for child or children & 32.3 & 22.6 & 34.2 & 38.1 & 25.6 & 26.6 \\
\hline Getting services for needs of child or children & 35.7 & 34.4 & 35.6 & 35.3 & 34.1 & 36.3 \\
\hline Having time to prepare healthy meals for child or children & 26.1 & 33.5 & 31.5 & 32.1 & 31.9 & 23.5 \\
\hline Being able to find nutritious foods & 23.7 & 20.5 & 23.3 & 28.9 & 22.8 & 17.0 \\
\hline Having safe food and drinking water & 31.1 & 12.9 & 16.4 & 25.7 & 21.4 & 21.2 \\
\hline Being able to afford nutritious foods & 24.1 & 22.2 & 26.0 & 20.6 & 25.9 & 19.5 \\
\hline Having mental health services for child or children & 13.3 & 15.6 & 23.3 & 12.8 & 16.4 & 13.3 \\
\hline Having mental health services for parents or caregivers & 15.5 & 17.1 & 12.3 & 15.6 & 17.1 & 13.9 \\
\hline
\end{tabular}


Table 4 Needs in health and wellbeing based on degree, employment, and number of young children (\%)

\begin{tabular}{|c|c|c|c|c|c|c|c|}
\hline \multirow[t]{2}{*}{ Indicators } & \multicolumn{2}{|l|}{ Degree } & \multicolumn{3}{|c|}{ Employment } & \multicolumn{2}{|c|}{ Children } \\
\hline & Below bachelor & $\begin{array}{l}\text { Bachelor } \\
\text { or above }\end{array}$ & Full time & Part time & Other & $0-1$ & $1+$ \\
\hline Understanding child or children's development & 52.0 & 44.3 & 45.7 & 59.9 & 47.1 & 46.6 & 52.0 \\
\hline Finding healthcare providers for child or children & 27.1 & 27.0 & 29.2 & 21.8 & 26.2 & 27.3 & 26.9 \\
\hline Taking child or children to well-child visits & 32.0 & 28.2 & 30.2 & 30.9 & 32.0 & 30.5 & 30.5 \\
\hline Being able to afford healthcare for child or children & 33.1 & 30.7 & 34.0 & 28.6 & 27.9 & 34.3 & 29.4 \\
\hline Being able to get to healthcare as needed for child or children & 30.3 & 24.7 & 28.4 & 23.7 & 33.7 & 28.0 & 28.3 \\
\hline Getting services for needs of child or children & 34.4 & 35.9 & 35.0 & 33.2 & 37.8 & 32.2 & 39.3 \\
\hline Having time to prepare healthy meals for child or children & 25.4 & 35.1 & 32.2 & 22.1 & 27.3 & 30.2 & 28.1 \\
\hline Being able to find nutritious foods & 24.7 & 19.0 & 19.9 & 25.2 & 26.7 & 22.2 & 22.5 \\
\hline Having safe food and drinking water & 26.1 & 15.7 & 19.0 & 31.7 & 20.3 & 17.1 & 29.4 \\
\hline Being able to afford nutritious foods & 23.6 & 22.1 & 23.2 & 19.5 & 23.8 & 23.3 & 22.5 \\
\hline Having mental health services for child or children & 14.4 & 15.7 & 13.8 & 13.0 & 19.2 & 15.4 & 13.8 \\
\hline Having mental health services for parents or caregivers & 15.9 & 16.1 & 14.8 & 14.9 & 18.6 & 17.1 & 14.2 \\
\hline
\end{tabular}

Table 5 Binary logistic regression results of needs in health and wellbeing (Odds ratio)

\begin{tabular}{|c|c|c|c|c|c|}
\hline Indicators & Race/Ethnicity & Age & Employment & Degree & Children \\
\hline Understanding child or children's development & $\begin{array}{l}1.19(\mathrm{~B}) \\
0.98(\mathrm{O})\end{array}$ & $\begin{array}{l}0.86(26-40) \\
0.95\left(40^{+}\right)\end{array}$ & $\begin{array}{l}1.54(\mathrm{P})^{*} \\
0.96(\mathrm{O})\end{array}$ & 0.87 & 1.08 \\
\hline Finding healthcare providers for child or children & $\begin{array}{l}1.29(\mathrm{~B}) \\
1.41(\mathrm{O})\end{array}$ & $\begin{array}{l}0.62(26-40)^{*} \\
0.50\left(40^{+}\right)^{*}\end{array}$ & $\begin{array}{l}0.64(\mathrm{P})^{*} \\
0.80(\mathrm{O})\end{array}$ & 1.12 & 0.97 \\
\hline Taking child or children to well-child visits & $\begin{array}{l}0.91(\mathrm{~B}) \\
1.03(\mathrm{O})\end{array}$ & $\begin{array}{l}0.76(26-40) \\
0.58\left(40^{+}\right)^{*}\end{array}$ & $\begin{array}{l}1.04(\mathrm{P}) \\
1.06(\mathrm{O})\end{array}$ & 0.92 & 0.96 \\
\hline Being able to afford healthcare for child or children & $\begin{array}{l}1.22(\mathrm{~B}) \\
1.27(\mathrm{O})\end{array}$ & $\begin{array}{l}1.03(26-40) \\
0.91\left(40^{+}\right)\end{array}$ & $\begin{array}{l}0.83(\mathrm{P}) \\
0.79(\mathrm{O})\end{array}$ & 0.88 & $0.74 *$ \\
\hline Being able to get to healthcare as needed for child or children & $\begin{array}{l}1.57(\mathrm{~B})^{*} \\
1.80(\mathrm{O})^{*}\end{array}$ & $\begin{array}{l}0.60(26-40)^{*} \\
0.64\left(40^{+}\right)^{*}\end{array}$ & $\begin{array}{l}0.68(\mathrm{P})^{*} \\
1.24(\mathrm{O})\end{array}$ & 0.90 & 0.91 \\
\hline Getting services for needs of child or children & $\begin{array}{l}1.05(\mathrm{~B}) \\
1.17(\mathrm{O})\end{array}$ & $\begin{array}{l}0.95(26-40) \\
0.98(40+)\end{array}$ & $\begin{array}{l}0.89(\mathrm{P}) \\
1.14(\mathrm{O})\end{array}$ & 1.21 & $1.37 *$ \\
\hline Having time to prepare healthy meals for child or children & $\begin{array}{l}0.88(\mathrm{~B}) \\
1.08(\mathrm{O})\end{array}$ & $\begin{array}{l}0.77(26-40) \\
0.45\left(40^{+}\right)^{*}\end{array}$ & $\begin{array}{l}0.68(\mathrm{P})^{*} \\
1.02(\mathrm{O})\end{array}$ & $1.82 *$ & 1.01 \\
\hline Being able to find nutritious foods & $\begin{array}{l}1.12(\mathrm{~B}) \\
1.28(\mathrm{O})\end{array}$ & $\begin{array}{l}0.81(26-40) \\
0.52\left(40^{+}\right)^{*}\end{array}$ & $\begin{array}{l}1.35(\mathrm{P}) \\
1.48(\mathrm{O})\end{array}$ & 0.98 & 0.91 \\
\hline Having safe food and drinking water & $\begin{array}{l}2.49(\mathrm{~B})^{*} \\
1.06(\mathrm{O})\end{array}$ & $\begin{array}{l}1.12(26-40) \\
1.15\left(40^{+}\right)\end{array}$ & $\begin{array}{l}1.48(\mathrm{P})^{*} \\
0.90(\mathrm{O})\end{array}$ & 0.88 & $1.71^{*}$ \\
\hline Being able to afford nutritious foods & $\begin{array}{l}1.20(\mathrm{~B}) \\
1.32(\mathrm{O})\end{array}$ & $\begin{array}{l}1.42(26-40) \\
0.98\left(40^{+}\right)\end{array}$ & $\begin{array}{l}0.78(\mathrm{P}) \\
1.16(\mathrm{O})\end{array}$ & 0.95 & 0.88 \\
\hline Having mental health services for child or children & $\begin{array}{l}0.94(\mathrm{~B}) \\
1.69(\mathrm{O})\end{array}$ & $\begin{array}{l}1.28(26-40) \\
0.88\left(40^{+}\right)\end{array}$ & $\begin{array}{l}1.07(\mathrm{P}) \\
1.84(\mathrm{O})^{*}\end{array}$ & 1.24 & 0.82 \\
\hline Having mental health services for parents or caregivers & $\begin{array}{l}0.94(\mathrm{~B}) \\
0.60(\mathrm{O})\end{array}$ & $\begin{array}{l}1.16(26-40) \\
0.85\left(40^{+}\right)\end{array}$ & $\begin{array}{l}1.12(\mathrm{P}) \\
1.63(\mathrm{O})^{*}\end{array}$ & 1.10 & 0.75 \\
\hline
\end{tabular}

*Indicates statistical significance. For race/ethnicity, White is the reference group, B represents Black, O represents Other; For age, 25 or younger is the reference group; For employment, full-time is the reference group, P represents part-time, O represents other; For degree, below bachelor is the reference group; For the number of children, those with no or 1 young child is the reference group

other ethnicity/race identities selected "Being able to get to healthcare as needed" as a priority, with Black parents/ caregivers $(\mathrm{OR}=1.57)$ and the parents/caregivers of other ethnicity/race identities $(\mathrm{OR}=1.80)$ reporting significantly greater likelihood of selecting this item as a priority while controlling other variables in the model.

Age appeared to make a difference in the priorities of parents/caregivers regarding some aspects of health and 
wellbeing. For example, about $38 \%$ of the parents/caregivers who were 25 or younger, $26 \%$ of those who were between 26 and 40 years of age, and $27 \%$ of those who were older than 40 selected "Being able to get to healthcare as needed" as a priority. About $37 \%$ of the parents/caregivers who were 25 or younger and $26 \%$ of those who were older than 40 selected "Taking child or children to well-child visits" as a priority. About $29 \%$ of the parents/caregivers who were 25 or younger and $17 \%$ of those who were older than 40 selected "Being able to find nutritious foods" as a priority. The binary logistic regression analysis revealed parents/ caregivers who were 25 or younger had significantly greater likelihood of selecting these items as priorities while controlling other variables in the model.

Parents/caregivers holding different academic degrees reported differences in their priorities for some aspects in health and wellbeing. For example, $35 \%$ of parents/caregivers with a bachelor's degree or above and $25 \%$ of those who were yet to earn a bachelor's degree selected "Having time to prepare healthy meals" as a priority. The parents/caregivers with a bachelor's degree or above reported significantly greater likelihood of selecting this item as a priority while controlling other variables in the model $(\mathrm{OR}=1.82)$.

Participants' employment status also seemed related to priorities of parents/caregivers regarding health and wellbeing. About $60 \%$ of the partially employed parents/caregivers and $46 \%$ of the fully employed ones selected "Understanding child or children's development" as a priority. About 32\% of the partially employed parents/caregivers and $19 \%$ of the fully employed ones selected "Having safe food and drinking water" as a priority. The binary logistic regression analysis revealed that the parents/caregivers who were partially employed had significantly greater likelihood of selecting the two items as priorities while controlling other variables in the model with the odds ratios of 1.54 and 1.48 respectively. About $32 \%$ of the fully employed parents/caregivers and $22 \%$ of those who were partially employed selected "Having time to prepare healthy meals" as a priority. The binary logistic regression analysis revealed that the parents/ caregivers who were fully employed had significantly greater likelihood of selecting this item as a priority while controlling other variables in the model.

Number of young children was also associated with the priorities of parents/caregivers regarding health and wellbeing. About $29 \%$ of the parents/caregivers with two or more young children and $17 \%$ of those with one or no young child selected "Having safe food and drinking water" as a priority. About $39 \%$ of the parents/caregivers with two or more young children and $32 \%$ of those with one or no young child selected "Getting services for needs of child or children" as a priority. The binary logistic regression analysis revealed that the parents/caregivers with two or more young children had significantly greater likelihood of selecting the two items as priorities while controlling other variables in the model with the odds ratios of 1.71 and 1.37 respectively. About $34 \%$ of the parents/caregivers with one or no young child and $29 \%$ of those with two or more young children selected "Being able to afford healthcare" as a priority. The binary logistic regression analysis revealed that the parents/caregivers with one or no young child had significantly greater likelihood of selecting this item as a priority while controlling other variables in the model $(\mathrm{OR}=0.74)$.

\section{Needs or Priorities Related to Family Environment}

We compared the perspectives of parents/caregivers, organizational representatives, and community members regarding the priorities with respect to family environment (Table 6). More than half of the parents/caregivers selected "Having enough family time to spend with child/children" and "Having strong relationships with child or children" as priorities. About half of the organizational representatives

Table 6 Needs in family environment $(\%)(\mathrm{N}=2680)$

\begin{tabular}{|c|c|c|c|}
\hline Indicators & $\begin{array}{l}\text { Parents/ } \\
\text { Caregivers }\end{array}$ & $\begin{array}{l}\text { Organizational repre- } \\
\text { sentatives }\end{array}$ & $\begin{array}{l}\text { Community } \\
\text { members }\end{array}$ \\
\hline Having enough family time to spend with child/children & 54.0 & 35.6 & 36.1 \\
\hline Having strong relationships with child or children & 50.3 & 43.2 & 34.2 \\
\hline Having a support system of friends and family members available & 41.4 & 44.7 & 38.2 \\
\hline Feeling safe at home & 26.6 & 28.7 & 25.5 \\
\hline Having community resources and activities to support family life & 38.7 & 49.1 & 46.1 \\
\hline Being in a family-friendly community & 34.9 & 20.9 & 28.5 \\
\hline Feeling safe in the community & 33.8 & 29.1 & 37.6 \\
\hline Having a voice/place in the community & 21.1 & 17.0 & 22.4 \\
\hline Having role models in the community & 16.0 & 18.4 & 18.2 \\
\hline Having amenities in the community & 32.5 & 27.3 & 27.3 \\
\hline Having a community free of litter, rundown housing, and vandalism & 16.5 & 12.5 & 20.6 \\
\hline
\end{tabular}


selected "Having community resources and activities to support family life" and "Having a support system of friends and family members available" as priorities. Fewer than half community members (46.1\%) selected "Having community resources and activities to support family life" as a priority.

We analyzed the perspectives of parents/caregivers regarding family environment by considering their race/ ethnicity, age, academic degree, employment status, and number of young children (Tables 7 and 8 ). We used binary logistic regression analyses to examine the prediction of age, race/ethnicity, academic degree, employment status, and number of young children on their selection of priorities. Odds ratios (OR) were reported in Table 9.

Parents/caregivers of different ethnicity/races demonstrated differences in their priorities for some aspects in family environment. For example, about $27 \%$ of White parents/caregivers and $49 \%$ of Black parents/caregivers selected "Having community resources and activities to support family life" as a priority. About $12 \%$ of White parents/caregivers and $28 \%$ of Black parents/caregivers selected "Having a voice/place in the community" as a priority. The binary logistic regression analysis revealed Black parents/ caregivers reported significantly greater likelihood in selecting these items as priorities while controlling other variables in the model. About $63 \%$ of White parents/caregivers and $46 \%$ of Black parents/caregivers selected "Having enough family time to spend with child/children" as a priority, with White parents/caregivers having significantly greater likelihood in selecting this item as a priority.

Age appeared to make a difference in the priorities of parents/caregivers regarding some aspects of family environment. For example, about $59 \%$ of the parents/caregivers who were 25 or younger and $44 \%$ of those who were older than 40 selected "Having enough family time to spend with child/ children" as a priority. About $32 \%$ of the parents/caregivers who were 25 or younger and $21 \%$ of those who were older

Table 7 Needs in family environment based on ethnicity/race and age (\%)

\begin{tabular}{|c|c|c|c|c|c|c|}
\hline \multirow[t]{2}{*}{ Indicators } & \multicolumn{3}{|c|}{ Race/Ethnicity } & \multicolumn{3}{|l|}{ Age } \\
\hline & Black & White & Other & $26^{-}$ & $26-40$ & $40^{+}$ \\
\hline Having enough family time to spend with child/children & 45.6 & 63.1 & 53.4 & 59.2 & 57.9 & 43.9 \\
\hline Having strong relationships with child or children & 45.6 & 54.6 & 60.3 & 50.5 & 51.1 & 49.3 \\
\hline Having a support system of friends and family members available & 41.0 & 42.0 & 45.2 & 42.2 & 42.3 & 39.7 \\
\hline Feeling safe at home & 25.4 & 27.6 & 27.4 & 31.7 & 27.8 & 21.2 \\
\hline Having community resources and activities to support family life & 49.1 & 27.2 & 42.5 & 40.4 & 35.7 & 43.6 \\
\hline Being in a family-friendly community & 29.4 & 39.5 & 45.2 & 35.8 & 34.9 & 33.7 \\
\hline Feeling safe in the community & 36.0 & 31.6 & 35.6 & 35.3 & 32.4 & 35.4 \\
\hline Having a voice/place in the community & 28.0 & 12.0 & 27.4 & 28.0 & 18.9 & 20.7 \\
\hline Having role models in the community & 19.5 & 12.0 & 19.2 & 20.6 & 15.6 & 14.4 \\
\hline Having amenities in the community & 33.4 & 31.4 & 32.9 & 33.9 & 33.6 & 30.0 \\
\hline Having a community free of litter, rundown housing, and vandalism & 16.2 & 15.6 & 21.9 & 17.4 & 16.5 & 16.1 \\
\hline
\end{tabular}

Table 8 Needs in family environment based on degree, employment, and number of young children (\%)

\begin{tabular}{|c|c|c|c|c|c|c|c|}
\hline \multirow[t]{2}{*}{ Indicators } & \multicolumn{2}{|l|}{ Degree } & \multicolumn{3}{|c|}{ Employment } & \multicolumn{2}{|c|}{ Children } \\
\hline & Below bachelor & $\begin{array}{l}\text { Bachelor } \\
\text { or above }\end{array}$ & Full time & Part time & Other & $0-1$ & $1+$ \\
\hline Having enough family time to spend with child/children & 51.2 & 57.3 & 60.5 & 38.2 & 50.0 & 58.9 & 46.8 \\
\hline Having strong relationships with child or children & 48.2 & 53.4 & 53.1 & 46.6 & 42.4 & 51.5 & 48.6 \\
\hline Having a support system of friends and family members available & 41.9 & 41.0 & 41.3 & 42.0 & 41.3 & 41.6 & 41.1 \\
\hline Feeling safe at home & 28.9 & 22.5 & 27.9 & 25.6 & 22.7 & 26.2 & 27.1 \\
\hline Having community resources and activities to support family life & 38.6 & 38.6 & 36.0 & 45.4 & 38.4 & 35.4 & 43.5 \\
\hline Being in a family-friendly community & 33.0 & 37.7 & 36.0 & 26.3 & 41.9 & 38.1 & 30.2 \\
\hline Feeling safe in the community & 33.4 & 34.0 & 34.2 & 35.1 & 31.4 & 32.0 & 36.4 \\
\hline Having a voice/place in the community & 23.7 & 17.3 & 18.2 & 24.4 & 26.2 & 19.6 & 23.5 \\
\hline Having role models in the community & 18.2 & 13.2 & 16.8 & 16.4 & 11.6 & 15.0 & 17.4 \\
\hline Having amenities in the community & 30.7 & 35.5 & 32.7 & 32.8 & 30.2 & 32.2 & 33.0 \\
\hline Having a community free of litter, rundown housing, and vandalism & 16.1 & 17.1 & 17.1 & 13.4 & 19.2 & 15.8 & 17.6 \\
\hline
\end{tabular}


Table 9 Binary logistic regression results of needs in family environment (Odds Ratio)

\begin{tabular}{|c|c|c|c|c|c|}
\hline Indicators & Race/Ethnicity & Age & Employment & Degree & Children \\
\hline Having enough family time to spend with child/children & $\begin{array}{l}0.49(\mathrm{~B})^{*} \\
0.62(\mathrm{O})^{*}\end{array}$ & $\begin{array}{l}0.67(26-40)^{*} \\
0.37\left(40^{+}\right)^{*}\end{array}$ & $\begin{array}{l}0.47(\mathrm{P})^{*} \\
0.67(\mathrm{O})^{*}\end{array}$ & 0.97 & $0.71 *$ \\
\hline Having strong relationships with child or children & $\begin{array}{l}0.65(\mathrm{~B})^{*} \\
1.31(\mathrm{O})\end{array}$ & $\begin{array}{l}0.83(26-40) \\
0.77\left(40^{+}\right)\end{array}$ & $\begin{array}{l}0.84(\mathrm{P}) \\
0.66(\mathrm{O})^{*}\end{array}$ & 1.07 & 1.02 \\
\hline Having a support system of friends and family members available & $\begin{array}{l}0.96(\mathrm{~B}) \\
1.16(\mathrm{O})\end{array}$ & $\begin{array}{l}1.00(26-40) \\
0.93\left(40^{+}\right)\end{array}$ & $\begin{array}{l}1.07(\mathrm{P}) \\
1.09(\mathrm{O})\end{array}$ & 1.00 & 0.97 \\
\hline Feeling safe at home & $\begin{array}{l}0.75(\mathrm{~B}) \\
1.03(\mathrm{O})\end{array}$ & $\begin{array}{l}0.82(26-40) \\
0.57\left(40^{+}\right)^{*}\end{array}$ & $\begin{array}{l}0.86(\mathrm{P}) \\
0.69(\mathrm{O})\end{array}$ & $0.69 *$ & 1.05 \\
\hline Having community resources and activities to support family life & $\begin{array}{l}2.87(\mathrm{~B})^{*} \\
2.21(\mathrm{O})^{*}\end{array}$ & $\begin{array}{l}1.00(26-40) \\
1.36\left(40^{+}\right)\end{array}$ & $\begin{array}{l}1.28(\mathrm{P}) \\
1.28(\mathrm{O})\end{array}$ & $1.61 *$ & 1.30 \\
\hline Being in a family-friendly community & $\begin{array}{l}0.69(\mathrm{~B})^{*} \\
1.03(\mathrm{O})\end{array}$ & $\begin{array}{l}0.79(26-40) \\
0.69\left(40^{+}\right)\end{array}$ & $\begin{array}{l}0.76(\mathrm{P}) \\
1.50(\mathrm{O})^{*}\end{array}$ & 1.16 & $0.76^{*}$ \\
\hline Feeling safe in the community & $\begin{array}{l}1.22(\mathrm{~B}) \\
1.24(\mathrm{O})\end{array}$ & $\begin{array}{l}0.91(26-40) \\
1.09\left(40^{+}\right)\end{array}$ & $\begin{array}{l}0.95(\mathrm{P}) \\
0.85(\mathrm{O})\end{array}$ & 1.12 & 1.23 \\
\hline Having a voice/place in the community & $\begin{array}{l}2.64(\mathrm{~B})^{*} \\
2.63(\mathrm{O})^{*}\end{array}$ & $\begin{array}{l}0.71(26-40) \\
0.72\left(40^{+}\right)\end{array}$ & $\begin{array}{l}1.22(\mathrm{P}) \\
1.73(\mathrm{O})^{*}\end{array}$ & 1.10 & 1.02 \\
\hline Having role models in the community & $\begin{array}{l}1.69(\mathrm{~B})^{*} \\
1.78(\mathrm{O})\end{array}$ & $\begin{array}{l}0.77(26-40) \\
0.75\left(40^{+}\right)\end{array}$ & $\begin{array}{l}0.82(\mathrm{P}) \\
0.61(\mathrm{O})\end{array}$ & 0.84 & 1.07 \\
\hline Having amenities in the community & $\begin{array}{l}1.23(\mathrm{~B}) \\
1.06(\mathrm{O})\end{array}$ & $\begin{array}{l}0.93(26-40) \\
0.74\left(40^{+}\right)\end{array}$ & $\begin{array}{l}1.03(\mathrm{P}) \\
1.03(\mathrm{O})\end{array}$ & $1.48^{*}$ & 1.06 \\
\hline Having a community free of litter, rundown housing, and vandalism & $\begin{array}{l}1.10(\mathrm{~B}) \\
1.75(\mathrm{O})\end{array}$ & $\begin{array}{l}0.89(26-40) \\
0.85\left(40^{+}\right)\end{array}$ & $\begin{array}{l}0.76(\mathrm{P}) \\
1.17(\mathrm{O})\end{array}$ & 1.19 & 1.22 \\
\hline
\end{tabular}

*Indicates statistical significance. For race/ethnicity, White is the reference group, B represents Black, O represents Other; For age, 25 or younger is the reference group; For employment, full-time is the reference group, P represents part-time, O represents other; For degree, below bachelor is the reference group; For the number of children, those with no or 1 young child is the reference group

than 40 selected "Feeling safe at home" as a priority. The binary logistic regression analysis revealed parents/caregivers who were 25 or younger had significantly greater likelihood of selecting the two items as priorities.

Parents/caregivers holding different academic degrees reported differences in their priorities for some aspects of the family environment. For example, $36 \%$ of parents/caregivers with a bachelor's degree or above and $31 \%$ of those who were yet to earn a bachelor's degree selected "Having amenities in the community" as a priority, with parents/caregivers with a bachelor's degree or above reporting significantly greater likelihood of selecting this item as a priority $(\mathrm{OR}=1.48)$. About $23 \%$ of parents/caregivers with a bachelor's degree or above and $29 \%$ of those who were yet to earn a bachelor's degree selected "Feeling safe at home" as a priority, with parents/caregivers who were yet to earn a bachelor's degree reporting significantly greater likelihood of selecting this item as a priority $(\mathrm{OR}=0.69)$.

Additionally, participants' employment status was associated with the priorities of parents/caregivers regrading family environment. For example, about $61 \%$ of the fully employed parents/caregivers and $38 \%$ of the partially employed ones selected "Having enough family time to spend with child/children" as a priority, with the parents/ caregivers who were fully employed having significantly greater likelihood in selecting this item as a priority while controlling other variables in the model. About $18 \%$ of the fully employed parents/caregivers and $26 \%$ of the parents/ caregivers in the other employment status selected "Having a voice/place in the community" as a priority, with the parents/caregivers who were in the other employment categories having significantly greater likelihood of selecting the item as a priority.

Finally, the number of young children was also associated with the priorities of parents/caregivers regarding health and wellbeing. About $47 \%$ of the parents/caregivers with two or more young children and 59\% of those with one or no young child selected "Having enough family time to spend with child/children" as a priority. About $30 \%$ of the parents/caregivers with two or more young children and 38\% of those with one or no young child selected "Being in a family-friendly community" as a priority. The binary logistic regression analysis revealed that the parents/caregivers with one or no young child had significantly greater likelihood of selecting the two items as priorities while controlling other variables in the model with the odds ratios of 0.71 and 0.76 respectively.

\section{Regional Meetings}

The analysis of regional meetings revealed four overarching goals related to health, wellbeing, and family environment 
respectively, along with related strategies for implementation. Regarding health and wellbeing, the goal identified most often across meetings was to increase access to early intervention for children (Goal 1). Children with identified delays should be referred to early intervention and receive timely services. Strategies included universal developmental screening, wellness and mental health support for teachers of young children, and greater communication regarding availability of services. Goal 2 was to ensure that all children are physically and mentally healthy. Strategies included providing parents and children with mental health services, promoting healthy diet, building partnerships with communities, and educating parents. Goal 3 was to provide mental health services for children and family members. Strategies included promoting social/emotional screening, educating on Adverse Childhood Experiences (ACEs) and protective factors, caring for the mental health of staff members, providing professional development for teachers, and increasing pay to improve retention of effective teachers and staff. Goal 4 was to modify the systems to support and promote self-sufficiency. Strategies included providing incentives for steps toward success. Decision-makers should modify system requirements and regulations, and introduce life skills, home economics, and financial literacy in middle/ high schools.

In addition, regional meetings revealed major barriers across all health and wellbeing goals. These barriers included: (1) Logistical concerns (timeliness of early intervention, lack of collaboration among statewide systems), (2) Accessibility concerns (unawareness of the access to services, lack of bilingual materials and staff, lack of service in rural areas, lack of transportation), (3) Financial concerns (no dedicated funding, lack of paid parental/maternity leave), (4) Perceptions of health and wellbeing (stigma of early intervention, abuse, and mental health services, cultural barriers), (5) Retention and quality concerns (length of hiring process, high turnover among teachers/caregivers), and (6) Food related concerns (food cost, lack of fresh food, lack of knowledge about healthy food).

Similarly, four overarching goals were identified regarding family environment and accompanying strategies. Goal 1 was to build communities that are family friendly. Strategies included helping families overcome transportation barriers to programs, connecting families to resources and events, and fostering cultural sensitivity. Goal 2 was to support all families. Strategies included establishing partnership and collaboration among community organizations, building relationships with families, and providing home visiting programs. Goal 3 was to address the needs of diverse families and develop cultural sensitivity. Strategies included supporting dual language learners, providing greater outreach to a variety of cultural groups, providing cultural diversity training to parents and teachers, and establishing partnerships with organizations that provide coordinated services. Goal 4 was to ensure legislators understand their impact and ability to influence families and children. Strategies included building trustful relationships with legislators, informing legislators of the needs of children and families, and hosting town hall meetings through which legislators could hear directly from parents.

Further, regional meetings also revealed six major barriers to achieving the goals related to family environment. These barriers included: (1) Equity concerns (resources availability due to language and cultural differences, lack of ESOL services), (2) Accessibility concerns (location of services, lack of transportation); (3) Financial concerns (limited funds, unfunded mandates); (4) Perceptions of families (unawareness of parents need, lack of intentional and individualized services); (5) Organizational concerns (lack of coordination among agencies, competitions and territorialism, lack of staff from diverse backgrounds); and (6) Political concerns (politicization of social issues, legislators' lack of interest in or knowledge about child development and equity issues, legislators turnover are unapproachability).

\section{Focus Groups Results}

Coding based on the focus group interviews revealed two overarching goals with respect to the needs of prekindergarten children in the domains of health, wellbeing, and family environment. The first key theme was to provide safe living and learning environments for all children. Participants shared that all children deserve to grow up in a safe, nurturing, loving, inclusive, and healthy environment. Children should feel safe and accepted and have role models made up of family, community, and school. For example, one participant indicated "When children have a loving environment, they tend to flourish." In particular, participants emphasized the impact of parenting and family relations on child development, noting that children have the need to feel loved and have their parents involved in their lives. In addition, communities should initiate programs that raise parents' awareness of the resources and support, increase parental involvement, and provide parent education. Families should have access to mentoring and counseling programs, transportation to the programs and services, community activities, and safe outdoor spaces and activities.

Another important theme was to provide solid supporting systems and services for the health and wellbeing of all children. All children should have access to affordable highquality childcare services and health care services. Children should have access to comprehensive and individualized services including childcare, speech/occupational therapy, services to support children with disabilities, and mental health resources and services. Parents should be involved in promoting children's health and wellbeing. Parents should 
be educated on child development and the availability of resources that support child health and wellbeing. Participants emphasized that communities should listen to families and provide programs and services according to the specific needs of the children and families.

Regarding the current community programs and services, participants shared mixed views. Some showed satisfaction, indicating their communities provided a variety of supporting programs and services (e.g., parents workshops, partnership with other organizations) for families. Others shared frustrations and disappointments, indicating their communities were not doing well or not doing enough. Families were sometimes not aware of the programs or resources, they were not able to participate due to lack of money or transportation, and some families even viewed agencies as adversarial and distrusting.

Participants reported various barriers and obstacles that prevent the implementation of programs that support child health, wellbeing and family involvement. The major barriers included availability and affordability of childcare, transportation to childcare for people in the rural areas, and parents' knowledge and involvement. Many parents were not involved due to unawareness of the resources and services, lack of knowledge about child development, and work schedules. Participants identified that children with special needs, children from minority ethnic and cultural backgrounds, and high-poverty or low-income families needed the most urgent support. Finally, participants indicated the importance of communication and collaboration among schools, families, communities, and organizations. Priorities should also include a focus on building positive relationships and collaboration, understanding cultural and ethnic diversities, and correctly identifying needs of children. As one county indicated, "The top priorities in the community would be to not only have these conversations, but to create action plans that will bring changes in the community."

\section{Discussion}

This research employed a convergent mixed-methods design and incorporated three data collection methods to investigate the needs of prekindergarten children with a focus on health, wellbeing, and family environment. When using complementary mixing strategies (Bazeley \& Kemp, 2012) to examine results across all data collection techniques (state-wide survey, multiple regional meetings, and focus groups that involved a total of 4615 stakeholders), we drew informative conclusions (Table 10). Six emerging priorities were identified across groups to support young children's health, wellbeing, and family environments. These priorities related to three constructs: accessibility, knowledge, and support. In terms of accessibility, two priorities emerged. Stakeholders prioritized children and parents/caregivers having the ability to find and use community services that might support families. In addition, making childcare available and affordable emerged as a priority related to accessibility. In terms of knowledge, the importance of understanding child development across stakeholders was seen as a main priority. In terms of support, stakeholders identified three priorities: having enough family time, building strong relationships with children, and fostering community support for families. While these priorities also relate to relationships, participants described the need for additional support in terms of money or family time to establish positive relationships with children.

In addition to informing the strategic plan through these results, we found more emphasis is needed in recognizing distinct priorities of parents/caregivers of different socio-demographic backgrounds (e.g., ethnicity/race, employment, education, age, number of young children). Specifically, Black parents/caregivers were more likely
Table 10 Goals and priorities based on three data collection techniques

\begin{tabular}{lll}
\hline Methods & Health and wellbeing & Family environment \\
\hline Survey & Understanding child development & Having enough family time \\
& Getting services for children & Building strong relationships \\
& Affordability of childcare & Having community resources \\
& & Support from friends and family \\
Regional meetings & Accessibility to early care/intervention & Family friendly communities \\
& Ensuring physical and mental health & Family support system \\
& Providing mental health services & Diversity and cultural sensitivity \\
& Promoting self-sufficiency & Involving legislators \\
Focus groups & Affordability of high-quality childcare & Family support and relationship \\
& Accessibility to high-quality childcare & Community involvement \\
& Providing mental health services & Parenting knowledge/education \\
& Having knowledge on child development & Accessibility to programs \\
& Providing services for children with disabilities & Cultural and ethnic diversities \\
\hline
\end{tabular}


to consider it a priority to have safe food and drinking water, have transportation to healthcare, have community resources, and have a voice and role models in the community. Parents/caregivers who were not fully employed were more likely to consider it a priority to understand child development, have safe food and drinking water, live in a family-friendly community, and have a voice in the community. Parents who had not earned a bachelor's degree yet were more likely to prioritize feeling safe at home. Further analyses of the relationships of ethnicity/race and employment and education of the parents/caregivers who participated in the survey revealed that among the White parents/caregivers, about $57 \%$ had a bachelor's degree or above and $70 \%$ were employed full-time. However, among the Black parents/caregivers, about $23 \%$ had a bachelor's degree or above and $57 \%$ were employed full-time. These findings echo those in an unpublished study by the same research team, indicating that there was an association between the socio-demographic identities of parents/caregivers and the choices of their priories regarding early childhood education. Similarly, Jain et al. (2020) suggested that families from racially, ethnically, and linguistically diverse backgrounds demonstrated distinct needs.

These findings combined with the overall convergence of participants' perceived needs relating to accessibility and support highlight the social justice issues so prevalent in early childhood. While families are concerned with identifying and accessing high quality child care for their children, these sites are few and far between, and therefore are not always a viable option for many families across the state. When considering Bronfenbrenner's theory (1986) that the combined effect of multiple microsystems on children's growth and development, it is imperative to address the implicit bias and systemic inequities that are undeniably present in education, socioeconomic status, accessibility, knowledge, and support.

In addition to the ethnicity/race, education, and employment of parents/caregivers, we also examined the associations of their age and number of young children and their choices of priorities regarding child needs. We found that young parents/caregivers ( 25 or younger) were more likely to consider it a priority to find healthcare providers, have transportation to healthcare and well-child visits, be able to find nutritious food, have time to prepare healthy meals, feel safe at home, and have enough family time with their children. In addition, parents/caregivers with two or more young children were more likely to consider it a priority to have safe food and drinking water and get services for their children, while those with one or no young child were more likely to consider it a priority to be able to afford healthcare, have enough family time with child/children, and live in a family-friendly community. These distinct priorities based on the age and number of young children of parents/caregivers should also be considered in developing and implementing early childhood intervention programs to support child development.

The findings of this study provide valuable information and could contribute to three areas: research, policy, and practice in the field of child development. First, this study sheds some light on the research literature of child development and needs assessment, especially in understanding the priorities of child needs regarding health, wellbeing, and family environment. Various studies explored perceptions of health and wellbeing (e.g., Easthope \& White, 2006), program effectiveness (e.g., Ludwig \& Miller, 2007), children with special health care needs (e.g., Chen \& Cisler, 2011), family literacy (e.g., Crawford \& Zygouris-Coe, 2006), and disadvantaged families (e.g., Magnuson et al., 2004). However, limited research focused on identifying the needs of children and families. This study was expected to fill this gap, and future studies could replicate this study or investigate further based on the findings of this study.

Second, the findings of this study can be used to inform policy making and funding decisions in support of early childhood learning and development. Stakeholders should be aware of and acknowledge the common priorities identified, the socio-demographic backgrounds of children and families, and the importance of diversity and cultural sensitivity in policy making in child development. Understanding child development and child needs based on theory and empirical study could inform legislators and policymakers to make policy that could better serve children and families. For example, this study revealed that children and families from different socio-demographic backgrounds reported their unique needs in terms of health, wellbeing, and family environment. The early intervention policy and funding should navigate various support including information support, material support, and emotional support (McWilliam \& Scott, 2001) to the children and families with unique needs. For children and families from disadvantaged backgrounds, the framework of access to quality early childhood education and care (ECEC) by Archambault et al. (2020) is an appropriate guide in policy making and in child development. While the findings presented in this study represent perceived needs for young children from a variety of stakeholders, including parents and educators, it does not address why these needs are prioritized in the first place. Increased interventions and supports related to establishing safe spaces where families have access to clean water and food, access to healthcare, and access to high quality childcare are required to ensure equity across all groups. Results from this work may look very different if these supports were already in place for all families across South Carolina.

Third, the findings are beneficial for developing and implementing intervention programs that target children and families based on their unique needs. Recognizing 
the ethnic/racial differences of child needs is essential in developing and implementing early childhood intervention programs. Specifically, to address the ethnic/racial disparities in terms of access to services, program implementation should target the barriers that contribute to the disparities, which include time, location, cost, difficulties in engaging families, and lack of perceived needs (Bornheimer et al., 2018; Green et al., 2020; Haine-Schlagel \& Walsh, 2015). Family-centered practices of early intervention have been promoted by childcare researchers and practitioners. Familycentered interventions focus on having positive relationships with families, meeting families' needs, and giving families meaningful decision-making opportunities (McWilliam, 2010). In addition, educators, researchers, practitioners, childcare workers, community members, and policy makers should acknowledge the barriers rooted in systems across the health and education sectors. Early childhood intervention programs should employ a culturally responsive approach in the design, development, and implementation of the programs. Most importantly, health policy should be implemented through the neighborhoods and communities of concentrated disadvantage, and a broad and diverse coalition of organizations is needed to increase public support and advance health and wellbeing (Biglan et al., 2020) to promote child and family health and mental health.

As Crawford and Zygouris-Coe (2006) stated "The concept of family literacy is as simple as schools and families working together for the best education of children, and as complex as integrating the multi-faceted academic and social systems that impact literacy learning in our society" (p. 266). Findings from focus groups also revealed the needs and importance of communication and collaboration among schools, families, communities, and organizations. Therefore, we call for joint efforts and collaboration among families, schools, communities, organizations, and early childhood professionals to support the learning and development of all children regardless of their diverse backgrounds. Strong and positive collaborations are needed among early childhood professionals who have shared goals, responsibilities, accountability, and resources to support early learning and development (Friend \& Cook, 2017). Most importantly, professionals should overcome various barriers (e.g., liability concerns, information sharing, funding, training) to ensure meaningful collaboration (Weglarz-Ward et al., 2020).

\section{Limitations}

A few limitations in addition to those described previously in the study design should be noted. First, although the study was based on a large-scale statewide needs assessment that involved almost 5000 participants, we believe that the findings might not be fully and completely generalized to all children and families in the state. The responses collected through the survey, regional meetings, and focus groups were voluntary and were the result of convenience and snowball sampling techniques. Future studies should seek to use a random sampling method to gain a full picture of child needs in the state. Second, we analyzed the sociodemographic information of parents/caregivers including age, ethnicity/race, education, employment, and number of young children in the investigation of their choices of priorities. We believe other factors including family income, neighborhood, primary language spoken at home, and housing instability should be included in future studies. In addition, we recommend that in-depth interviews should be conducted with parents/caregivers to understand the specific needs of children and families, especially those who have experienced trauma, absent resources, or other challenges.

\section{Conclusion}

This study investigated the needs of prekindergarten children with a focus on health, wellbeing and family environment. Through the lens of multiple stakeholders, we identified common priorities in child development as well as the unique priorities based on parents/caregivers of different socio-demographic backgrounds. We agree with the statements by the World Health Organization (2021) that "investing in children is one of the most important things a society can do to build a better future" and that "children must be given a stable environment in which to thrive, including good health and nutrition, protection from threat and access to opportunities to learn and grow." We believe that child needs are influenced by the global and national environment. For example, the global pandemic, COVID-19, has caused a devastating impact on young children, especially those from disadvantaged families. The needs of the children and families impacted by this pandemic should be identified in order to provide urgent and substantial support for them. Most importantly, early childhood programs should be culturally responsive, and needs assessment, as an on-going dynamic process, should be incorporated into the programs of early learning and development. Child development requires joint effort from various stakeholders. The stakeholders should always commit to establishing social justice, equity, diversity, and inclusion in the development and implementation of intervention programs to support early learning and development.

Acknowledgements The authors would like to acknowledge the support and input from Michele Bowers at South Carolina Department of Social Services, Georgia Mjartan and Cassie Barber at South Carolina First Steps, Laura Johns at Propulsion Squared, Montana Cain at The Forum for Youth Investment, Reginald Williams at South Carolina 
State University, Artie Maharaj at Massachusetts Institute of Technology, the staff of First Steps Partnerships in all 46 counties, and the members of the South Carolina Preschool Development Grant Collaborative.

Funding This work was funded through a Preschool Development Grant from the Administration for Children and Families/US Department of Health and Human Services administered by the South Carolina Department of Social Services.

\section{References}

Archambault, J., Côté, D., \& Raynault, M. F. (2020). Early childhood education and care access for children from disadvantaged backgrounds: Using a framework to guide intervention. Early Childhood Education Journal, 48, 345-352.

Bazeley, P., \& Kemp, L. (2012). Mosaics, triangles, and DNA: Metaphors for integrated analysis in mixed methods research. Journal of Mixed Methods Research, 6(1), 55-72.

Biglan, A., Elfner, K., Garbacz, S. A., Komro, K., Prinz, R. J., Weist, M. D., \& Zarling, A. (2020). A strategic plan for strengthening America's families: A brief from the coalition of behavioral science organizations. Clinical Child and Family Psychology Review, $23,153-175$.

Bornheimer, L. A., Acri, M. C., Gopalan, G., \& McKay, M. M. (2018). Barriers to service utilization and child mental health treatment attendance among poverty-affected families. Psychiatric Services, 69, 1101-1104.

Bronfenbrenner, U. (1986). Ecology of the family as a context for human development: Research perspectives. Developmental Psychology, 22(6), 723-742.

Bronfenbrenner, U. (2005). Making human beings human: Bioecological perspectives on human development. Sage Publications Ltd.

Chen, H. Y., \& Cisler, R. A. (2011). Assessing health-related quality of life among children with special health care needs in the United States. Children's Health Care, 40, 311-325.

Chetty, R., Hendren, N., \& Katz, L. F. (2016). The effects of exposure to better neighborhoods on children: New evidence from the moving to opportunity experiment. American Economic Review, 106(4), 855-902.

Clay, M. M. (1966). Emergent reading behaviour. Unpublished doctoral dissertation, University of Auckland Library, Auckland, New Zealand.

Corbin, C. B., Lindsey, R., Welk, G. J., \& Corbin, W. R. (2002). Concepts of fitness and wellness: A comprehensive lifestyle approach. (4th ed.). McGraw-Hill.

Corbin, C. B., \& Pangrazi, R. P. (2001). Toward a uniform definition of wellness: A commentary. President's Council on Physical Fitness and Sports Research Digest, 3, 1-8.

Corbin, J., \& Strauss, A. (2008). Basics of qualitative research: Techniques and procedures for developing grounded theory. (3rd ed.). Sage.

Crawford, P. A., \& Zygouris-Coe, V. (2006). All in the family: Connecting home and school with family literacy. Early Childhood Education Journal, 33(4), 261-267.

Creswell, J. W., \& Plano Clark, V. L. (2018). Designing and conducting mixed methods research. (3rd ed.). Sage.

Dunst, C. J., Hamby, D., Trivette, C. M., Raab, M., \& Bruder, M. B. (2000). Everyday family and community life and children's naturally occurring learning opportunities. Journal of Early Intervention, 23, 151-164.
Dunst, C. J., Trivette, C. M., \& Hamby, D. W. (2006). Technical manual for measuring and evaluating family support program quality and benefits. Winterberry Press.

Dunst, C. J., Trivette, C. M., \& Hamby, D. W. (2008). Research synthesis and meta-analysis of studies of family-centered practices. Winterberry Press.

Easthope, G., \& White, R. (2006). Health and Wellbeing: How do young people see these concepts? Youth Studies Australia, 25(1), $42-49$.

Friend, M. P., \& Cook, L. (2017). Interactions: Collaboration skills for school professionals. (8th ed.). Pearson Education.

Frisvold, D. E., \& Lumeng, J. C. (2011). Expanding exposure: Can increasing the daily duration of head start reduce childhood obesity? Journal of Human Resources, 46(2), 373-402.

Fryer, R. G., \& Levitt, S. D. (2006). The Black-White test score gap through third grade. American Law and Economics Review, 8(2), 249-281.

Ginsburg, K. R. (2007). The importance of play in promoting healthy child development and maintaining strong parent-child bonds. Pediatrics, 119(1), 182-191.

Green, J. G., McLaughlin, K. A., Fillbrunn, M., Fukuda, M., Jackson, J. S., Kessler, R. C., \& Alegría, M. (2020). Barriers to mental health service use and predictors of treatment drop out: Racial/ ethnic variation in a population-based study. Administration and Policy in Mental Health, 47, 606-616.

Haine-Schlagel, R., \& Walsh, N. E. (2015). A review of parent participation engagement in child and family mental health treatment. Clinical Child and Family Psychology Review, 18, 133-150.

Hanline, M. F., Milton, S., \& Phelps, P. C. (2010). The relationship between preschool block play and reading and maths abilities in early elementary school: A longitudinal study of children with and without disabilities. Early Child Development and Care, 180, $1005-1017$.

Jacobs, K. (2004). Parent and child together time. In B. H. Wasik (Ed.), Handbook of family literacy. (pp. 193-212). Erlbaum.

Jain, S., Reno, R., Cohen, A. K., Bassey, H., Master, M., \& Nichols, C. R. (2020). A family-centered mixed-methods needs assessment for the system of care for young children with social-emotional and behavioral concerns. Children and Youth Services Review, $117,105243$.

Johnson, R. B., \& Onwuegbuzie, A. J. (2004). Mixed methods research: A research paradigm whose time has come. Educational Researcher, 33(7), 14-26.

Kalil, A., Ryan, R., \& Corey, M. (2012). Diverging destinies: Maternal education and the developmental gradient in time with children. Demography, 49(4), 1361-1383.

Kiefer, R. A. (2008). An integrative review of the concept of wellbeing. Holistic Nursing Practice, 22, 244-252.

Landry, S. H., Smith, K. E., \& Swank, P. R. (2006). Responsive parenting: Establishing early foundations of social, communication, and independent problem solving skills. Developmental Psychology, 42, 627-642.

Larson, J. S. (1999). The conceptualization of health. Medical Care Research and Review, 56, 123-136.

Linder, S. M., \& Emerson, A. (2019). Increasing family mathematics play interactions through a take-home math bag intervention. Journal of Research in Childhood Education, 33(3), 323-344.

Linder, S. M., Ramey, M. D., \& Zambak, S. (2013). Predictors of success for school readiness: A selective review of the literature. Early Childhood Research and Practice, 15(1), 1.

Ludwig, J., \& Miller, D. L. (2007). Does head start improve children's life chances? Evidence from a discontinuity design. Quarterly Journal of Economics, 122(1), 159-208.

Magnuson, K. A., Meyers, M. K., Ruhm, C. J., \& Waldfogel, J. (2004). Inequality in preschool education and school readiness. American Educational Research Journal, 41(1), 115-157. 
Magnuson, K., \& Waldfogel, J. (2016). Trends in income-related gaps in enrollment in early childhood education: 1968 to 2013. AERA Open, 2(2), 1-13.

McWilliam, R. A., \& Scott, S. (2001). A support approach to early intervention: A three-part framework. Infants and Young Children, $13,55-66$.

McWilliam, R. A. (2010). Working with families of young children with special needs. Guilford Press.

Mol, S. E., Bus, A. G., De Jong, M. T., \& Smeets, D. J. H. (2008). Added value of dialogic parent book readings: A meta-analysis. Early Education and Development, 19, 7-26.

Moore, K. A., Murphey, D., \& Bandy, T. (2012). Positive child wellbeing: An index based on data for individual children. Maternal and Child Health Journal, 16, 119-128.

Newacheck, P. W., Hung, Y. Y., \& Wright, K. K. (2002). Racial and ethnic disparities in access to care for children with special health care needs. Ambulatory Pediatrics, 2, 247-254.

Park, J. M., Ostler, T., \& Fertig, A. (2015). Physical and psychological aggression towards a child among homeless, doubled-up, and other low-income families. Journal of Social Services Research, 41(3), 413-423.

Ramey, G., \& Ramey, V. A. (2010). The rug rat race. Brookings Papers on Economic Activity, 41, 129-176.

Reardon, S. F. (2011). The widening socioeconomic status achievement gap: New evidence and possible explanations. In R. J. Murnane \& G. J. Duncan (Eds.), Whither opportunity? Rising inequality and the uncertain life chances of low-income children. Russell Sage Foundation.

Rossin-Slater, M. (2015). Promoting health in early childhood. Future of Children, 25(1), 35-64.

Senechal, M., \& Young, L. (2008). The effect of family literacy interventions on children's acquisition of reading from kindergarten to grade 3: A meta-analytic review. Review of Educational Research, 78, 880-907.

Simon, A. E., Chan, K. S., \& Forrest, C. B. (2008). Assessment of children's health-related quality of life in the United States with a multidimensional index. Pediatrics, 121, e118-e126.

Spurr, S., Bally, J., Ogenchuk, M., \& Walker, K. (2012). A framework for exploring adolescent wellness. Pediatric Nursing, 38, 320-326.

U. S. Census Bureau Subject definitions. (2020). Retrieved November 2020, from https://www.census.gov/programs-surveys/cps/techn ical-documentation/subject-definitions.html\#: :text=Hispanic\% 20White\%20origin.-,Family,as\%20members\%20of\%20one\% 20family.

U. S. Census Bureau. (2019). United States of America. Retrieved November 2020, from https://data.census.gov/cedsci/profile?g= 0100000US.

U.S. Department of Health and Human Services, Health Resources and Services Administration, Maternal and Child Health Bureau. (2020). Children with special health care needs NSCH data brief. Retrieved November 2020, from https://mchb.hrsa.gov/sites/defau lt/files/mchb/Data/NSCH/nsch-cshcn-data-brief.pdf.

Verdine, B. N., Golinkoff, R. M., Hirsh-Pasek, K., \& Newcombe, N. S. (2014). Finding the missing piece: Blocks, puzzles, and shapes fuel school readiness. Trends in Neuroscience and Education, $3(1), 7-13$.

Weglarz-Ward, J. M., Santos, R. M., \& Hayslip, L. A. (2020). How professionals collaborate to support infants and toddlers with disabilities in child care. Early Childhood Education Journal, 48, 643-655.

Williams, R. (1983). Concepts of health: An analysis of lay logic. Sociology, 17(2), 185-205.

World Health Organization. (1946). WHO definition of health, preamble to the constitution of the world health organization as adopted by the international health conference, New York, 19-22 June, 1946. Official Records of the World Health Organization, 2, 100.

World Health Organization. (2021). Child health. Retrieved March 2021, from https://www.who.int/health-topics/child-health\#tab= tab_1.

Wright, T., Taub, A., Fetter, A., \& Shumpert, J. (2017). MMSD 4K: Pathways to resilience for children and families experiencing homelessness. Report for Madison Metropolitan School District. Retrieved November 2020, from http://mep.wceruw.org/resil ience-homelessness.html.

Ziol-Guest, K. M., \& McKenna, C. C. (2014). Early childhood housing instability and school readiness. Child Development, 85(1), 103-113.

Publisher's Note Springer Nature remains neutral with regard to jurisdictional claims in published maps and institutional affiliations. 